\title{
Evidence for linkage of nonsyndromic cleft lip with or without cleft palate to a region on chromosome 2
}

\author{
Joanna S Zeiger ${ }^{1, *}$, Jacqueline B Hetmanski ${ }^{1}$, Terri H Beaty ${ }^{1}$, Craig A VanderKolk ${ }^{2}$, \\ Diego F Wyszynski ${ }^{3}$, Joan E Bailey-Wilson ${ }^{4}$, Rosa Ortiz de Luna ${ }^{5}$, Claudia Perandones ${ }^{6,7}$, \\ Marie M Tolarova ${ }^{8}$, Terezie Mosby ${ }^{8}$, Ricardo Bennun ${ }^{7}$, Mabel Segovia $^{6}$, Pavel Calda ${ }^{9}$, \\ Elizabeth W Pugh ${ }^{2}$, Kim Doheny ${ }^{2}$ and Iain McIntosh ${ }^{2}$
}

${ }^{1}$ Bloomberg School of Public Health, Johns Hopkins University, Baltimore, MD, USA; ${ }^{2}$ School of Medicine, Johns Hopkins University, Baltimore, MD, USA; ${ }^{3}$ Boston University, School of Medicine, Boston, MA, USA; ${ }^{4}$ National Human Genome Research Institute, National Institutes of Health, Baltimore, MD, USA; ${ }^{5}$ Hospital Infantil de Mexico "Federico Gomez", Mexico City, Mexico; ${ }^{6}$ Centro Nacional de Genetica Medica, Buenos Aires, Argentina; ${ }^{7}$ Asociacion Piel, Buenos Aires, Argentina; ${ }^{8}$ University of the Pacific School of Dentistry, San Francisco, CA, USA; ${ }^{9} 1$ st Medical School Charles University, Prague, Czech Republic

Results from a genome-wide screen of 10 multiplex families ascertained through probands with nonsyndromic cleft lip with or without cleft palate (CL/P) in Mexico, Argentina, and the United States yielded suggestive evidence of linkage to chromosomes 2, 6, 17 and 18. Fine mapping excluded all regions except chromosome 2. Subsequent analysis was performed on the original 10 families plus an additional 16 families using 31 markers on chromosome 2. This analysis showed intriguing evidence of linkage to $2 q$ $(Z \mid r=2.26$, empirical $P$-value $=0.028$ in a chromosome-wide analysis). Transmission disequilibrium tests also revealed evidence of linkage and disequilibrium for two markers in this region (D2S168 and D2S1400 with $P$-values $=0.022$ and 0.006 , respectively). A subset of these 26 families provided additional evidence for a susceptibility gene for $C L / P$ on $2 q$, suggesting that further studies of genes in this region are warranted.

European Journal of Human Genetics (2003) 11, 835-839. doi:10.1038/sj.ejhg.5201052

Keywords: cleft lip and palate; linkage analysis; transmission disequilibrium test; chromosome 2

\section{Introduction}

Cleft lip with or without cleft palate $(\mathrm{CL} / \mathrm{P})$ is a common birth defect that represents a major public health burden, both socially and medically. The prevalence of $\mathrm{CL} / \mathrm{P}$ varies from 0.6 to 1.7 per 1000 livebirths among Caucasians, with African Americans showing a lower prevalence (0.4/1000) and Japanese having a higher frequency $(2.1 / 1000) .{ }^{1}$ Cleft lip and palate (CLP) and cleft lip (CL) comprise 45 and $25 \%$, respectively, of all children born with an oral cleft. ${ }^{2}$

*Correspondence: Dr Joanna S Zeiger, Department of Epidemiology, Room 6513, 615 N. Wolfe Street, Baltimore, MD 21205, USA. Tel: + $1410-$ 955 7961; Fax: + 1410 955-0863; E-mail: jzeiger@jhmi.edu Received 26 September 2002; revised 19 May 2003; accepted 21 May 2003
A population-based study in California showed that $62 \%$ of $\mathrm{CL} / \mathrm{P}$ births had no other major malformation. ${ }^{3}$ In all, $10-15 \%$ of all CL/P cases report a positive family history. ${ }^{4}$

Despite strong familial clustering, segregation analyses have not revealed consistent evidence for any single mode of inheritance for nonsyndromic CL/P. Various studies have suggested that $\mathrm{CL} / \mathrm{P}$ may follow a dominant or recessive model (with incomplete penetrance), a multifactorial threshold model and/or an oligogenic epistatic model. ${ }^{5,6}$ For example, Marazita et al, ${ }^{7}$ in a large study from England, suggested that CL/P may be controlled by an autosomal major gene with additional multifactorial contributions. Alternatively, Scapoli et $a l^{8}$ found evidence for a two-locus model with a dominant major gene and a recessive minor gene. 
The study of CL/P is further complicated by the fact that a combination of genetic and environmental factors contributes to its etiology. ${ }^{9}$ Linkage analysis of multiplex families and association studies using either case-control or family-based designs have become primary methods for identifying potential genes for $\mathrm{CL} / \mathrm{P} .{ }^{10,11}$ These two approaches do not always give consistent results, however. For example, the transforming growth factor alpha (TGFA) gene, located on chromosome $2 \mathrm{p} 13$, is the most widely studied candidate gene in $\mathrm{CL} / \mathrm{P}$ and has shown association with $\mathrm{CL} / \mathrm{P}$ in a number of case-control studies, but not in all. ${ }^{12}$ Most linkage studies of TGFA using multiplex families with nonsyndromic $\mathrm{CL} / \mathrm{P}$, on the other hand, have failed to show any evidence of linkage. ${ }^{13,14}$

Linkage studies have revealed several other candidate regions, recently reviewed in detail. ${ }^{11}$ Scapoli et al ${ }^{15}$ found significant linkage disequilibrium between the GABRB3 gene and CL/P. Evidence for linkage to chromosome 1p near the 5,10-methylenetetrahydrofoalte reductase locus and in the $1 \mathrm{q} 21$ and $1 \mathrm{q} 32-42.3$ regions $^{16}$ has been reported for CL/P. Regions on chromosomes $6 \mathrm{p}, 2 \mathrm{p}, 4 \mathrm{q}$ and $17 \mathrm{q}$ have all shown some evidence of linkage to $\mathrm{CL} / \mathrm{P}{ }^{17}$ Beiraghi et al ${ }^{18}$ found linkage to $4 \mathrm{q}$ in one family and Mitchell et $a l^{19}$ showed evidence of association to this same region, but a later study showed evidence against linkage in this region. ${ }^{20}$ Pezzetti et al ${ }^{21}$ reported a possible interaction between two regions that mapped in 6p23 and 2p13 in $38 \mathrm{CL} / \mathrm{P}$ multiplex families from Italy. However, Wong et $a l^{22}$ studied Swedish multiplex CL/P families, and found no evidence of linkage to selected candidate genes on chromosomes 2, 4, 6 or 19. Similarly, Marazita et al ${ }^{23}$ did not find significant linkage in any of these regions in $36 \mathrm{CL} / \mathrm{P}$ multiplex Chinese families. Stein et $a l^{24}$ found significant linkage with BCL3 on chromosome $19 \mathrm{q}$ in a fraction of their families. Wyszynski et $a^{25}$ and Martinelli et $a l^{26}$ failed to find further evidence of linkage to this marker, but they did find a significant association for an allele at this marker using the transmission disequilibrium test (TDT).

Using affected sib-pairs in a genomewide screen, Prescott et $a l^{27}$ identified 11 regions on eight chromosomes yielding nominally significant evidence of linkage (ie $P$-values $<0.05)$. These eight chromosomal regions were on chromosomes: 1p, 2p, 6p, 8q, 11 cen, 12q, 16p and Xcen-q. In the genome scan of their Chinese families, Marazita et $a^{23}$ had positive multipoint results for regions on chromosomes 1, 2, 3, 4, 6, 18 and 21. Statistically significant associations using the TDT were also found on chromosomes $3,4,5,6,7,11,12,16,20$ and 21 in these Chinese multiplex families. ${ }^{23}$

Identifying a genetic component involved in the etiology of $\mathrm{CL} / \mathrm{P}$ remains a challenge. Results of previous linkage studies have been largely inconclusive and often contradictory, hampered by the availability of only small pedigrees, modest numbers of multiplex families, varying racial and ethnic groups and, perhaps the unspecified role of environmental factors in the etiology of oral clefts. ${ }^{17}$ Here, we present the results of a genome-wide screen on 10 multiplex families with nonsyndromic $\mathrm{CL} / \mathrm{P}$ and the subsequent fine mapping regions on chromosome 2 in a total of 26 multiplex families.

\section{Methods \\ Multiplex families}

Multiplex families were recruited as part of our ongoing studies of nonsyndromic CL/P from a variety of sites, some of which have been described previously. ${ }^{25}$ In total, 10 multiplex families with sufficient biological samples for a genome-wide screen were available. Of these families, six were recruited from the Hospital Infantil de Mexico 'Federico Gomez', 14,25 two were from Buenos Aires (Argentina) and two were from the University of Iowa. In all, 59 individuals from these 10 families were genotyped (29 affected and 30 unaffected). A total of 368 microsatelite markers with an average intermarker distance of $9 \mathrm{~cm}$ and an average heterozygosity of 0.76 were genotyped by the Center for Inherited Disease Research (CIDR). After the analysis of the genome-wide screen data, additional microsatellite markers were identified in regions showing suggestions of linkage for fine mapping. In all, 16 additional multiplex families were added for these fine mapping efforts including: six families from Maryland, one family from Argentina and nine families from the Czech Republic. In these 26 multiplex families, a total of 137 individuals were genotyped. The mean family size was 9.2 individuals, ranging from a minimum of three family members to a maximum of 24 . There were a total of 74 affected individuals (40 male: 34 female) and 169 unaffected individuals (83 male: 86 female) in these 26 families.

\section{Statistical methods}

Since there is no clear model of inheritance for CL/P, nonparametric multipoint linkage analyses were carried out using GENEHUNTER (v2.0) and ASM (v.1.0). ${ }^{28,29}$ The Zlr scoring function under the exponential model was used to assess statistical significance of observed allele sharing identical-by-descent between all affected members in a family. When there are missing genotype data and/or small numbers of pedigrees, the Zlr score provides a good measure of excess allele sharing.

Under the null hypothesis of no linkage, 1000 replicate sets of these families were simulated from the framework map using the Merlin program ${ }^{30}$ and $Z$-all scores were computed with GENEHUNTER (v2.0) to compare against this test statistic from the observed data. This approach provided an empirical estimate of statistical significance tailored to the number of markers and the number of families considered here. Chromosome-wide empirical 
$P$-values were estimated separately for the original 10 families used in the genome-wide screen and for the 26 families used for fine mapping. In addition, single-point TDTs were carried out on the final sample of 26 families. These TDT statistics were computed using the sib-pair ${ }^{31}$ (v0.99) program for each the 31 individual markers on chromosome 2 .

\section{Results}

The initial genome-wide screen showed Zlr scores above 2 . 0 on chromosomes 2, 6, 17 and 18, and minor peaks on chromosomes 7 and 16. Subsequent fine mapping of these regions with additional markers failed to confirm evidence for linkage on chromosomes $6,7,16,17$ and 18 . Results of mapping on chromosome 2 in the initial 10 families are shown in Figure 1. For these 10 families (Argentinean, Iowan and Mexican), there were two peaks, one on $2 p$ at map position $26(\mathrm{Zlr}=3.19$, chromosome-wide empirical $P$-value $=0.058$ ) near markers D2S262 and D2S1400 and the other on $2 \mathrm{q}$ at position 248 ( $\mathrm{Zlr}=2.76$, chromosomewide empirical $P$-value $=0.158$ ) near marker D2S338.

All $26 \mathrm{CL} / \mathrm{P}$ multiplex families were used for fine mapping with 31 markers. The highest Zlr score for all families combined (thick solid line) occurred on $2 \mathrm{q}$ at position 247 near marker D2S338 $(\mathrm{Zlr}=2.56)$ (Figure 2). Marker D2S2968 on 2p (at map position 69) gave a Zlr score of 1.74. Chromosome-wide empirical $P$-values were calculated for both of these regions by generating 1000 replicates of these 26 families under the null hypothesis of no linkage to determine how often a Zlr score could be the same or higher than the observed Zlr score merely by chance. The peak on $2 \mathrm{q}$ showed an empirical $P$-value of 0.028 ; the empirical $P$-value for the peak on $2 p$ was only 0.49 .

Conditional linkage analysis was performed using the ASM (v1.0) program ${ }^{29}$ where families were weighted based on their nonparametric linkage (NPL) score at map position 247. Families with a positive NPL score at position 247 on chromosome $2 \mathrm{q}$ were assigned a weight of 1 , while families with a negative NPL score were assigned a weight of zero. As seen in Figure 2, Zlr scores in the 2p region were distinctly negative in those families yielding some evidence for linkage in the $2 \mathrm{q}$ region (dashed line). Families with negative NPL scores in the $2 \mathrm{q}$ region had positive NPL scores in the $2 p$ region (thin solid line).

Two individual markers on $2 p$ region yielded some evidence of linkage and disequilibrium in these 26 multiplex families. Allele 8 at marker D2S168 (map position 27) was transmitted to an affected child 15 times and not transmitted two times; allele 1 at marker D2S1400 (map position 27.6) was transmitted 23 times and not transmitted eight times (empirical global $P$-values, 0.022 and 0.006 , respectively).

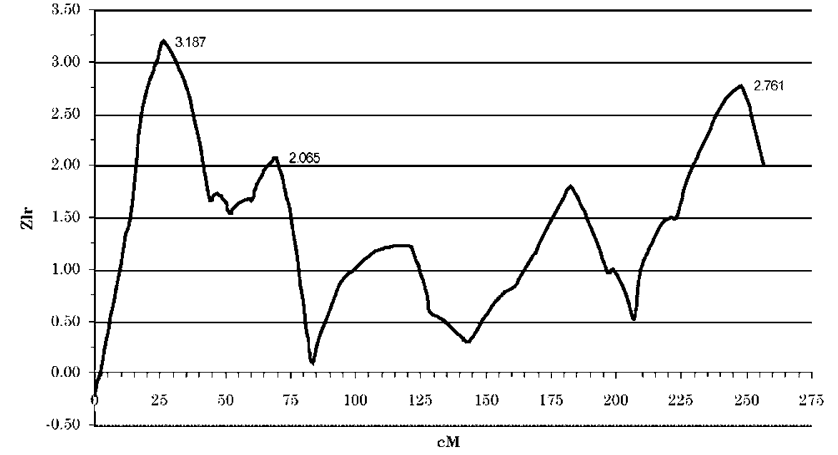

Figure 1 NPL scores for chromosome 2 on 10 multiplex nonsyndromic $\mathrm{CL} / \mathrm{P}$ families used in the genome-wide screen (25 markers).

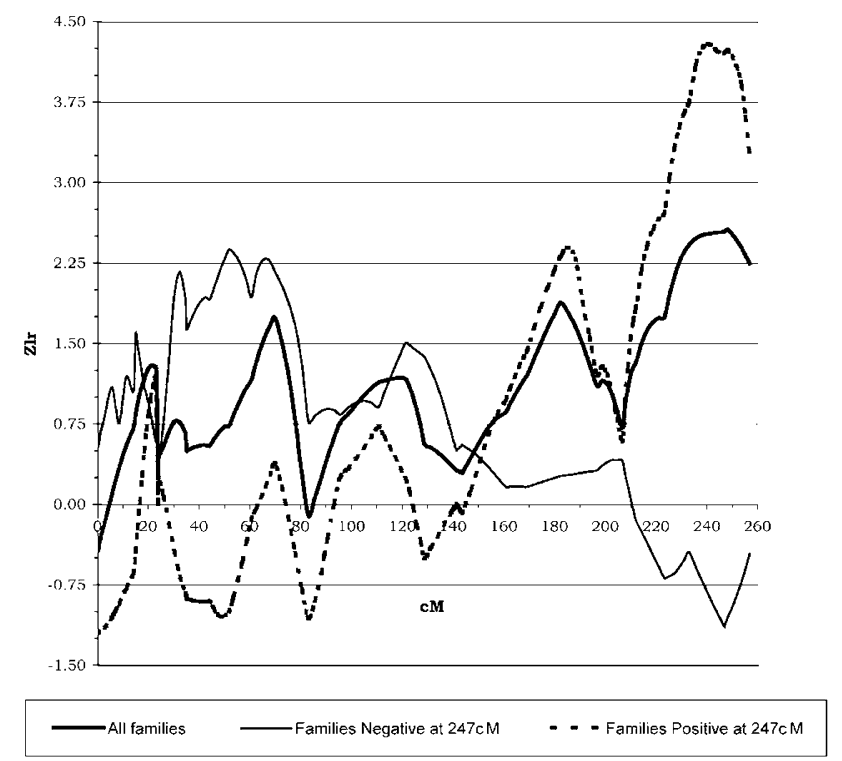

Figure 2 NPL scores for chromosome 2 on 26 multiplex nonsyndromic CL/P families using 31 markers.

\section{Discussion}

A genome-wide screen of 10 multiplex nonsyndromic CL/P famlies, and subsequent fine mapping of these 10 families plus an additional 16 families showed some evidence for linkage to two regions on chromosome 2. There was also evidence of linkage heterogeneity, however, with a subset of these 26 families showing evidence of linkage to 2q near marker D2S338 (map position $247 \mathrm{~cm}$ ), while the original 10 families had given stronger evidence for linkage in the $2 p$ region.

Marazita et $a l^{23}$ found LOD scores of 1.45 and 1.91 at D2S2944 $(210 \mathrm{cM})$ and D2S1363 $(227 \mathrm{cM})$, respectively, in 36 Chinese multiplex families with nonsyndromic CL/P. While the total NPL values in these regions were small, HLOD scores were $>1$, suggesting only a subset of their Chinese families was responsible for this evidence of 
linkage. Additionally, in another study, two families exhibiting CLP with mild facial dysmorphism showed evidence of linkage to $2 \mathrm{q} 35-36 .^{32}$ Whether these two studies have identified the same or different susceptibility genes remains to be determined.

D2S338 lies $10 \mathrm{Mb}$ distal of D2S1363 and the intervening region does not include any previously reported candidate genes for CL/P. It is possible that the linkage observed in this study is being driven by only one or two families, with one family (from Mexico) yielding evidence for the $2 p$ region and another family (from Iowa) at the $2 \mathrm{q}$ region. It is clear that linkage heterogeneity exists among these multiplex families where certain genes may be important in different racial, ethnic or geographic groups, further complicating the effort to map genes for CL/P.

It is interesting to note that different results were obtained using TDT and NPL analyses. The strongest evidence of linkage was observed at $247 \mathrm{~cm}$ near marker D2S338; however, the TDT results yielded two markers showing excess transmission of an allele in the $2 p$ region (map position $27 \mathrm{~cm}$ ). Zlr scores in this region were $<1.0$. This phenomenon has been observed elsewhere in linkage studies of $\mathrm{CL} / \mathrm{P}$. While Stein et $a l^{24}$ found evidence of linkage to BCL3 on chromosome 19 , Wyszynski et al ${ }^{25}$ and Martinelli et $a l^{26}$ found no evidence from linkage analysis, but did show evidence of disequilibrium with alleles at BCL3 among CL/P cases using the TDT. Thus, it remains a challenge to resolve conflicting signals of linkage and linkage disequilibrium in family studies of $\mathrm{CL} / \mathrm{P}$, likely because multiple genes control its etiology.

\section{Acknowledgements}

Genotyping services for the genome scan were provided by the Center for Inherited Disease Research (CIDR). CIDR is fully funded through a federal contract from the National Institutes of Health to the Johns Hopkins University, Contract Number N01-HG-65403. Dr Wyszynski was funded by a contract from the Massachusetts Center for Birth Defects Research and Prevention of the Massachusetts Department of Public Health and by a research award from the Cleft Palate Foundation. We thank Adele Mitchell for her work on data from the genome-wide scan. This work was supported by Grant P60-DE13078.

\section{References}

1 Saal HM: Prenatal diagnosis: when the clinician disagrees with the patient's decision. Cleft Palate Craniofac J 2002; 39: $174-178$.

2 Gorlin R, Cohen MM, Levin LS: Syndromes of the head and neck, 3rd edn. New York: Oxford University Press, 1990.

3 Tolarova MM, Cervenka J: Classification and birth prevalence of orofacial clefts. Am J Med Genet 1998; 75: 126-137.

4 Fraser F: The genetics of cleft lip and cleft palate. Cleft Palate $J$ 1989; 26: 255-257.

5 Mitchell L, Risch N: Mode of inheritance of nonsyndromic cleft lip with or without cleft palate: a reanalysis. Am J Hum Genet 1992; 51: 323-332.
6 Wyszynski DF, Beaty TH, Maestri NE: Genetics of nonsyndromic oral clefts revisited. Cleft Palate Craniofacial J 1996; 33: 406-417.

7 Marazita ML, Goldstein AM, Smalley SL, Spence MA: Cleft lip with or without cleft palate: reanalysis of a three-generation family study from England. Genet Epidemiol 1986; 3: 335-342.

8 Scapoli C, Collins A, Martinelli M, Pezzetti F, Scapoli L, Tognon M: Combined segregation and linkage analysis of nonsyndromic orofacial cleft in two candidate regions. Ann Hum Genet 1999; 63: $17-25$.

9 Zeiger JS, Beaty TH: Gene-environment interaction and risk to oral clefts; in Wyszynski DF (ed): Cleft lip and palate: from origin to treatment. New York: Oxford University Press, 2002, pp 283-289.

10 Marazita ML, Neiswanger K: Association studies; in: Wyszynski DF (ed). Cleft lip palate: from origin to treatment. New York: Oxford University Press, 2002, pp 240-254.

11 Wyszynski DF: Locating genes for oral clefts in humans; in: Wyszynski DF (ed) Cleft lip and palate: from origin to treatment. New York: Oxford University Press, 2002, pp 255-264.

12 Mitchell L: Transforming growth factor alpha locus and nonsyndromic cleft lip with or without cleft palate: a reappraisal. Genet Epidemiol 1997; 14: 231-240.

13 Vintiner GM, Holder SE, Winter RM, Malcolm S: No evidence of linkage between the transforming growth factor-alpha gene in families with apparently autosomal dominant inheritance of cleft lip and palate. J Med Genet 1992; 29: 393-397.

14 Wyszynski DF, Maestri N, Lewanda AF et al: No evidence of linkage for cleft lip with or without cleft palate to a marker near the transforming growth factor alpha locus in two populations. Hum Hered 1997; 47: 101-109.

15 Scapoli L, Martinelli M, Pezzetti F et al: Linkage disequilibrium between GABRB3 gene and nonsyndromic familial cleft lip with or without cleft palate. Hum Genet 2002; 110: 15-20.

16 Martinelli M, Scapoli L, Pezzetti F et al: Linkage analysis of three candidate regions of chromosome 1 in nonsyndromic familial orofacial cleft. Annals of Hum Genet 2001; 65 (Part 5): 465-471.

17 Carinci F, Pezzetti F, Scapoli L, Martinelli M, Carinci P, Tognon M: Genetics of nonsyndromic cleft lip and palate: a review of international studies and data regarding the Italian population. Cleft Palate Craniofac J 2000; 37: 33-40.

18 Beiraghi S, Foroud T, Diouhy S et al: Possible localization of a major gene for cleft lip and palate to 4q. Clin Genet 1994; 6: $255-256$

19 Mitchell LE, Healey SC, Chenevix-Trench G: Evidence for an association between nonsyndromic cleft lip with or without cleft palate and a gene located on the long arm of chromosome 4. Am J Hum Genet 1995; 57: 1130-1136.

20 Blanton SH, Crowder E, Malcolm S et al: Exclusion of linkage between cleft lip with or without cleft palate and markers on chromosomes 4 and 6. Am J Hum Genet 1996; 58: 239-241.

21 Pezzetti F, Scapoli L, Martinelli M et al: A locus in 2p13-p14 (CL/ $\mathrm{P} 2)$, in addition to that mapped in $6 \mathrm{p} 23$, is involved in nonsyndromic familial orofacial cleft malformation. Genomics 1998; 50: 299-305.

22 Wong FK, Hagberg C, Karsten A et al: Linkage analysis of candidate regions in Swedish nonsyndromic cleft lip with or without cleft palate families. Cleft Palate Craniofac J 2000; 37: $357-362$.

23 Marazita ML, Field LL, Cooper ME et al: Genome scan for loci involved in cleft lip with or without cleft palate, in Chinese multiplex families. Am J Hum Genet 2002; 71: 349-364.

24 Stein J, Mulliken JB, Stal S et al: Nonsyndromic cleft lip with or without cleft palate: evidence of linkage to BCL3 in 17 multigenerational families. Am J Hum Genet 1995; 57: 257-272.

25 Wyszynski DF, Maestri N, McIntosh I et al: Evidence for an association between markers on chromosome $19 \mathrm{q}$ and nonsyndromic cleft lip with or without cleft palate in two groups of multiplex families. Hum Genet 1997; 99: 22-26.

26 Martinelli M, Scapoli L, Pezzetti F et al: Suggestive linkage between markers on chromosome 19q13.2 and nonsyndromic orofacial cleft malformation. Genomics 1998; 51: 177-181. 
27 Prescott NJ, Lees MM, Winter RM, Malcolm S: Identification of susceptibility loci for nonsyndromic cleft lip with or without cleft palate in a two stage genome scan of affected sib-pairs. Hum Genet 2000; 106: 345-350.

28 Kruglyak L, Daly MJ, Reeve-Daly MP, Lander ES: Parametric and nonparametric linkage analysis: a unified multipoint approach. Am J Hum Genet 1996; 58: 1347-1363.

29 Kong A, Cox NJ: Allele-sharing models: LOD scores and accurate linkage tests. Am J Hum Genet 1997; 61: 1179-1188.
30 Abecasis GR, Cardon LR, Cookson WO, Sham PC, Cherny SS: Association analysis in a variance components framework. Genet Epidemiol 2001; 21 (Suppl 1): S341-S346.

31 Duffy DL: SIB-PAIR (ver 0.99.9) A program for elementary genetical analyses, Queensland Institute of Medical Research Queensland, Australia http://www2.qimr.edu.au/davidD 2003.

32 Winter RM, Prescott NJ, Lees MM, Malcolm S: Refinement of a locus for a distinct syndrome of autosomal dominant cleft lip and palate to 2q35. Eur J Hum Genet 2002; 10 (Suppl 1): 218, Abstract P0683. 